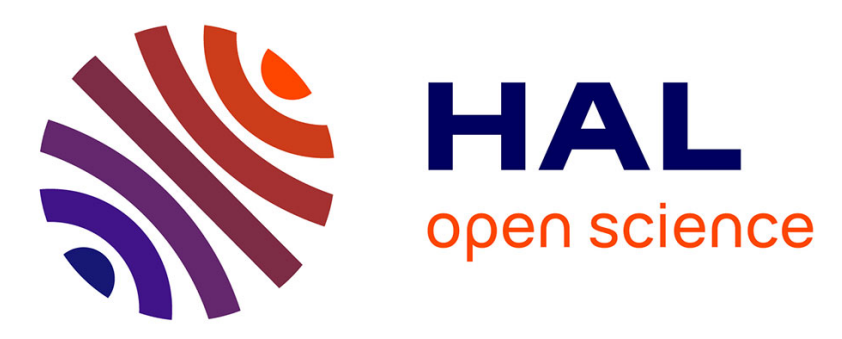

\title{
Nurturing Virtual Collaborative Networks into Urban Resilience for Seismic Hazards Mitigation
}

Giulia Cerè, Wanqing Zhao, Yacine Rezgui

\section{To cite this version:}

Giulia Cerè, Wanqing Zhao, Yacine Rezgui. Nurturing Virtual Collaborative Networks into Urban Resilience for Seismic Hazards Mitigation. 19th Working Conference on Virtual Enterprises (PROVE), Sep 2018, Cardiff, United Kingdom. pp.132-143, 10.1007/978-3-319-99127-6_12 . hal-02191157

\section{HAL Id: hal-02191157 \\ https://hal.inria.fr/hal-02191157}

Submitted on 24 Jul 2019

HAL is a multi-disciplinary open access archive for the deposit and dissemination of scientific research documents, whether they are published or not. The documents may come from teaching and research institutions in France or abroad, or from public or private research centers.
L'archive ouverte pluridisciplinaire HAL, est destinée au dépôt et à la diffusion de documents scientifiques de niveau recherche, publiés ou non, émanant des établissements d'enseignement et de recherche français ou étrangers, des laboratoires publics ou privés. 


\title{
Nurturing Virtual Collaborative Networks into Urban Resilience for Seismic Hazards Mitigation
}

\author{
Giulia Cerè, Wanqing Zhao and Yacine Rezgui \\ BRE Trust Centre for Sustainable Engineering, Cardiff School of Engineering, Cardiff Univer- \\ sity, CF243AB Cardiff, United Kingdom \\ cereg, zhaow9, rezguiy@cardiff.ac.uk
}

\begin{abstract}
A holistic analysis of the resilience of the built environment in relation to natural disasters needs to consider multidimensional parameters being interactive and mutually influencing each other as a collaborative network, including the physical side of the urban framework (e.g., structures and infrastructures) and the socio-organizational system (e.g., stakeholders, designers and governments). In this paper, an analysis is conducted to first provide a categorization of several dimensions that characterize the urban context, such as damage and structural typology, urban connectivity, building functionality. These factors have been then related to the resilience of the built environment in the context of the urban system considered as a collaborative network in order to point out the relevant interdependencies between its components. Particularly, this is meant to identify the relevant socio-organizational nodes, their interaction and how their collaboration can reflect on the physical network. The analysis is based on the real data from Old Beichuan, a town severely destroyed in the 2008 Wenchuan earthquake in China.
\end{abstract}

Keywords: Resilience, Collaborative networks, Built environment.

\section{Introduction}

Collaborative networks (CNs) consist of a set of autonomous entities geographically distributed, jointly working for the achievement of a shared goal and value creation [1]. The level of integration achieved in $\mathrm{CNs}$ is a characterizing factor that differentiate them from other virtually networked structures. In fact, this leads to data-rich collaboration where information are owned by the different entities with a continuous mutual exchange bringing more value than the simple sum of the knowledge contribution produced by the individual members [2]. The underlying idea behind CNs is then the enhanced value chain process resulting from the shared knowledge and high interconnectivity level between all the network components.

A CN is therefore constituted by a series of nodes that can be either considered as socio-organizational or physical. Examples of socio-organizational nodes can be private and public stakeholders, regulatory institutions and governmental authorities whereas physical nodes refer to structural and infrastructural elements, such as buildings, roads and energy-related institutions. Each node of the $\mathrm{CN}$ entails a specific function, hence for instance the regulatory one is in charge of devising the legislative standards that the planning and design nodes must comply to. Grounding of that, the response 
to a specific disruption provides an immediate indication of the level of collaboration between the different figures involved in the prevention, design and post-disaster management phases that should be iteratively be adapted according to the evolving nature of disasters [3].

Existing researches mainly combine the concepts of resilience and CNs to natural hazards separately while dealing with disaster risk management. On a large scale, several researches focus on the contribution of the individual entities involved in the resilience planning or they adopt a more governmental-based approach [4]. Interactive online mapping technologies are already in place where the historical patrimony of the building stock is significant [5], providing sectorial mapping of rural and urban areas, historical nucleuses and consolidated territorial planned zones. On a building level, the work proposed by Uzielli et al. [6] is a representative example of how to quantify resilience on a urban scale in face of soil-related disruptions and involving a multi-domain mapping for the characterization of the building stock. Cerè et al. [7] conversely presented an overview of resilience in face of natural hazards examining both qualitative and quantitative approaches.

On the other side, there is a growing trend in considering the concept of CNs together with resilience in face of natural hazards, although concrete applications have not been considered extensively. For example, the work devised by Jassbi et al. [2] draws the attention to the multifaceted nature of resilience and the need of overcoming traditional risk-based approaches in favor of a methodology enriched by the interrelations between the entities constituting the system, hence as a CN. Jung and Song [8] strengthened the existing linkage between CNs, resilience and disaster management, highlighting how the entities' fragmentation hinders the overall post-disaster response and it is not financially beneficial. The authors also underline the case-specificity of the "bonding and bridging effect" between the diverse network components, consisting in the inter-organizational connectivity within a specific $\mathrm{CN}$ [8]. Andrew and Carr [9] strengthen the underpinning concepts of trust and information-sharing between the actors of a $\mathrm{CN}$, calling for a collective recognition of the risk scenario and stronger consensus on the strategy to adopt.

The existing body of knowledge regarding $\mathrm{CNs}$ and resilience is therefore consistent and extensive, but not in terms of their practical implementation relatively to urban scenarios in face of natural hazards. The presented work aims at contextualizing the concept of $\mathrm{CNs}$ and resilience while dealing with seismic scenarios, considering the whole urban framework as a $\mathrm{CN}$ and identifying the relevant connections between both the physical (e.g., buildings and infrastructures) and virtual (e.g., stakeholders) components. The analysis focuses in particular on the county of Old Beichuan, in the aftermath of the 2008 Wenchuan Earthquake. Besides, the proposed research highlights the consequences of the fragmentation in CNs, leading to an insufficient resiliency level and resulting in poor preventive and post-disaster recovery measures [10].

The paper is structured into five sections, starting with an overview regarding the methodology devised for the research and followed in the third section by a detailed description of the mapping. Subsequently, the outcome of the mapping will be discussed in the fourth section followed by the conclusions in the fifth one. 


\section{$2 \quad$ Methodology and Study Area}

In this section the county of Old Beichuan is adopted as a case study aimed at contextualizing the presented research. Old Beichuan is located in the Wenchuan province in China, and has also been accounted amongst the most significantly damaged sites in the aftermath of the 2008 earthquake. The methodology adopted for the scope of the presented analysis is outlined in Figure 1 and entails three main phases (i.e., A, B and C). In first instance, the data-collection phase has been carried out throughout two field trips in December 2016 and July 2017, and the richest dataset has been gathered relatively to the central portion of Old Beichuan, since the remaining areas of the city (i.e., the northern and southern ones) were not directly accessible. The whole dataset included 3D laser scanning, photographic material and satellite imageries that allowed the comparison between pre and post site-conditions. These imageries have been gathered from the Google Earth database and particularly for the years 2001 and 2010. As part of the first work thread a preliminary site analysis has been carried out by manually mapping the whole building stock of the area in order to then compare it with the satellite imageries and photos. A schematic of the area available at the entrance of the Old Beichuan site allowed to identify the institutional buildings (e.g., transportation bureau, schools), while specific information regarding the functionality were gathered from panels spread in the site. It has to be pointed out that it is likely for some buildings to be lacking in the analysis because they have been completely destroyed and in the meantime the debris have been removed.

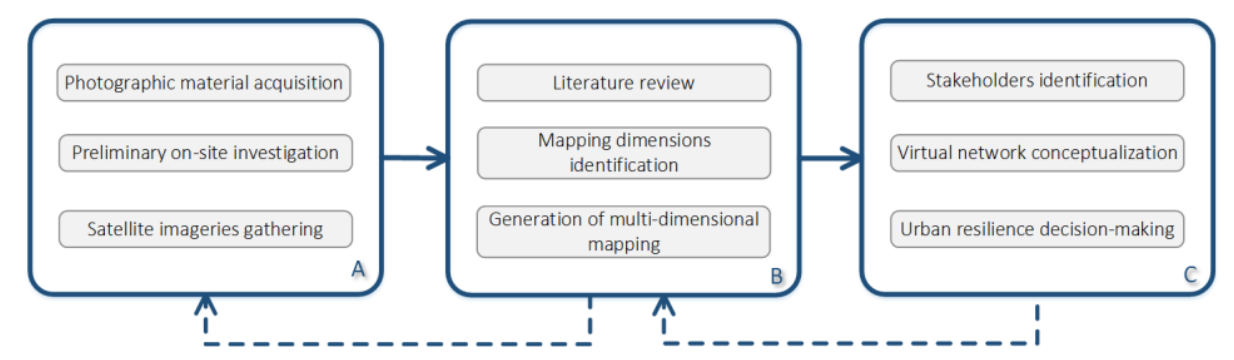

Fig. 1. Methodology overview

The second stage involved a literature review of existing qualitative damage scales for seismic-related hazards and the identification of the dimensions to include in the mapping. Following to that, the information regarding each dimension have contextually been added to the overlapped satellite imageries to characterize the physical network. Eventually, the third part of the work entailed the interpretation of the produced material considering the whole urban framework as a $\mathrm{CN}$ and implementing resilience in order to evaluate the response to the hazard. The mapping is therefore functional to the identification of the socio-organizational elements (i.e., nodes) of the $\mathrm{CN}$ and how their decision-making processes can influence the physical nodes in case of disruption. 


\section{Incorporating Collaborative Networks for Urban Resilience Analysis}

Scope of this work is to adopt the concept of CNs for the understanding of resilience in the context of a real case scenario in the aftermath of a seismic hazard and this section in particular focuses on the interrelations between the different nodes of the urban network. The focus is on how the socio-organizational ones can be related to resilience management and their influence on the physical network in the context of the urban framework as a $\mathrm{CN}$.

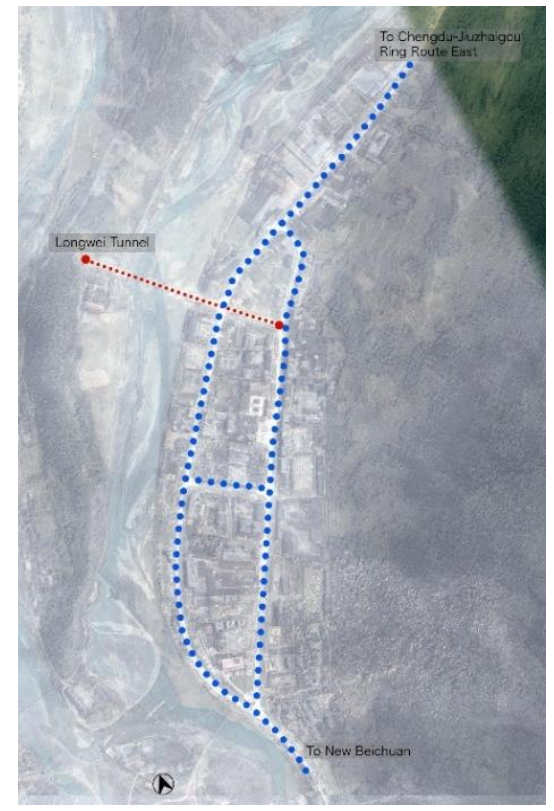

Fig. 2. Urban connectivity of Old Beichuan

Figures 2 and 5-6 show different levels of mapping as a result of the data-set analysis results overlapping to the 2010 post-earthquake satellite imagery gained from the Google Earth database, as previously described in section 2. Mainly, the multi-dimensional mapping involves the following:

- Road network system and connectivity with other urban centers, as in Figure 2.

- Damage level according to the qualitative site-specific scale, as in Figure 5a;

- Damage typology, as in Figure 5b;

- Building functionality, as in Figure 6a;

- Construction material (i.e., reinforced concrete framed buildings or masonry load bearing structures) as in Figure 6b. 


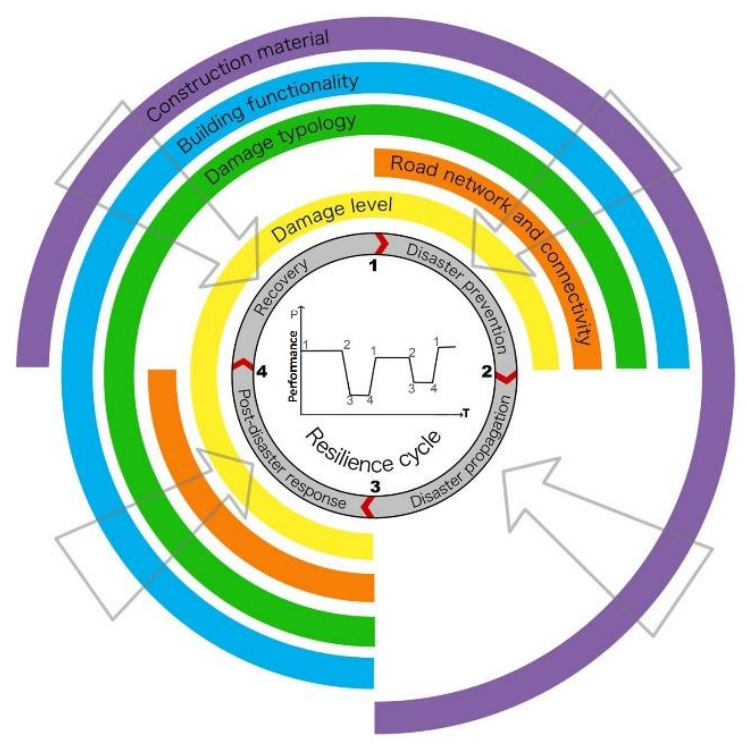

Fig. 3. Interdependencies between multi-dimensional mapping and resilience

Figure 3 highlights the specific influence of each mapped dimension on the main phases of resilience as identified by the literature [11] in mainly: disaster prevention, damage propagation, assessment and recovery. In particular, it is outlined how different factors can influence certain phases rather than others and this entails the involvement of specific socio-organizational nodes that have an influence on the physical network, as represented in Figure 4. For instance, stakeholders and clients have an influence on the technical and planning nodes, imposing financial constraints that therefore reflect on the construction technology and overall quality of the structure in the preventive phase. At the damage occurrence, this translates into specific damage levels and typologies which cannot be influenced anymore but they can be functional for post-disaster and recovery strategies for insurance companies, regulatory nodes and constructors. Given the cyclic nature of this process, information from previous disaster are vital for improving preventive strategies, as it can be seen in Figure 3 where it is highlighted that damage-related mapping have a significant impact on this phase.

The building functionality is a key aspect given its strong interrelations between the regulatory nodes and stakeholders. In fact, regulations establish specific categories of building defined as "strategic" (e.g., hospitals and schools) that are requested to comply higher performance levels. Normally these buildings are financed by public stakeholders, which should translate into more effective preventive measures and construction technologies, influencing both damage level and typology. The building functionality is also relevant for post-disaster and recovery phases. In fact, depending on damage level and typology, the technical nodes (e.g., planners, designers and engineers) have to collaborate with insurance companies to assess the financial entity of the damage and then inform occupants and stakeholders in respect to the required interventions for performance recovery. 
Figure 4 also shows how the different phases of resilience interlace with the CN structure and how they specifically influence each other. In particular, the mapping is the instrument functional for the socio-organizational nodes to characterize the physical network and understand where to intervene, since each dimension (e.g., damage type and level, construction technology) can be qualified and classified. Post-disaster response and recovery are mainly unidirectional actions resulting from decisions taken at the socio-organizational network level and impacting the physical nodes. Conversely, preventive strategies are mutually affected by both socio-organizational and physical nodes, since their development is nurtured by previous disruption information, as in Figure 3.

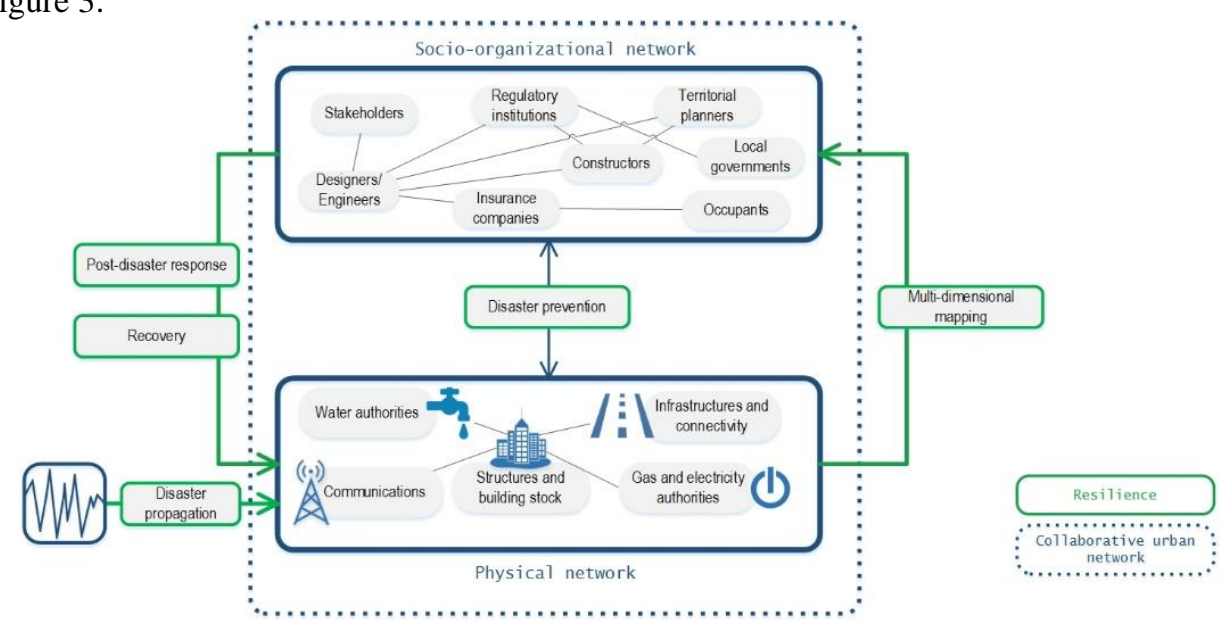

Fig. 4. Collaborative urban network conceptualization

As it can be observed both from Figure 3 and 4, the disaster propagation cannot actively be dumped other than intervening on preventive measures, which are key for a good resilient performance of the system and they are highly influenced by lessons learnt from previous disruptions. That is why damage level and typology mapping are vital to categorize the vulnerability of the physical system in face of potential future hazards, in a cyclic process as in Figures 3 and 4. Being the whole urban framework a highly interconnected network and considering the mutual influences of the different components as in Figure 3, it becomes clear that to improve the system's resilience it is required to intervene on the level of collaboration. Figure 3 shows in fact that a simultaneous coincidence of several domains in the same phase translates in a higher demand for collaboration. This means involving socio-organizational nodes with different domains of expertise in order to cover all the requested dimensions of analysis.

The consideration of the urban framework as a $\mathrm{CN}$ leads to understand that each network component (i.e., component of the network) is meant to be influenced by the others and at the same time it has an effect on other features. A scarce level of collaboration at the socio-organizational network level reflects in the poor performance of the physical network. 


\subsection{Qualitative Damage Assessment and Mapping Dimensions}

This section explores the specific development of the qualitative damage level scale, the identification of diverse disruption typologies in the context of Old Beichuan and their influence on the network resilience. Damage assessment has a vital relevance for post-disaster response and it creates knowledge for future preventive measures, informing the regulatory, planning and design nodes of the $\mathrm{CN}$. To this regard, a review involving landslide and earthquake-related damage scales for site-specific construction typologies (i.e., reinforced concrete (RC) and masonry structures) has been carried out in order to tailor the scale to the specific Chinese context.

Table 1. Adapted damage scale for seismic hazard for the Chinese context.

\begin{tabular}{lll}
\hline $\begin{array}{l}\text { Damage } \\
\text { Index }\end{array}$ & $\begin{array}{l}\text { Damage description for RC frames with } \\
\text { masonry infills }\end{array}$ & $\begin{array}{l}\text { Damage description for masonry } \\
\text { load-bearing walls buildings }\end{array}$ \\
\hline D0 & \multicolumn{2}{c}{ No damage } \\
D1 & $\begin{array}{l}\text { Negligible damage, building preserves its functionality with no need for repair } \\
\text { Structural elements show thin cracks, more } \\
\text { visible cracks on infill and non-structural } \\
\text { walls; building functionality not affected }\end{array}$ & $\begin{array}{l}\text { Secondary walls damaged; building } \\
\text { functionality not affected; minor re- } \\
\text { pairs are needed }\end{array}$ \\
& $\begin{array}{l}\text { Visible cracks on structural elements, se- } \\
\text { vere cracks on non-structural elements and } \\
\text { detachment of concrete from columns and } \\
\text { beams; infill walls collapsed partially; } \\
\text { building functionality compromised }\end{array}$ & $\begin{array}{l}\text { Minority of load-bearing walls dam- } \\
\text { aged, extensive cracks on load bear- } \\
\text { ing walls and roof. Overall func- }\end{array}$ \\
tionality compromised \\
D3 & $\begin{array}{l}\text { Minority of load-bearing walls damaged, } \\
\text { extensive cracks on load bearing walls and } \\
\text { roof. Overall functionality compromised. }\end{array}$ & $\begin{array}{l}\text { Majority of load-bearing walls dam- } \\
\text { aged and failure of pitched roofs. }\end{array}$ \\
& $\begin{array}{l}\text { Functionality severely compro- } \\
\text { mised. Building might not worth to } \\
\text { be repaired }\end{array}$ \\
D4 & $\begin{array}{l}\text { Sajority of load bearing walls se- } \\
\text { than 50\% of the building survives or it is } \\
\text { totally collapsed. }\end{array}$ & $\begin{array}{l}\text { jerely damaged, building stability } \\
\text { jeopardized or complete structural } \\
\text { failure. }\end{array}$ \\
\hline D5 & &
\end{tabular}

Three different damage scales have been analyzed and the definitive damage scale as in Table 1 is the result of a further calibration in light of the effective disruption level detected during the field investigations. The resulting damage scale involves structural and non-structural elements and concerns mainly two structural technologies (i.e., RC frames and masonry buildings) being the most popular types in mountainous Chinese areas [12] and in light of the field investigations in Old Beichuan. The first scale of damage analyzed was developed by Okada and Takai [13] and mainly deals with seismic hazards addressing RC structures, wooden frames and masonry buildings. The scale proposed by Mavrouli et al. [14] has been included given its consideration of structural and non-structural elements (e.g., infills and openings), in addition to its applicability to landslide scenarios. The author also involved the development of fragility 
curves, which cannot be adopted in the context of Old Beichuan site, given the predominantly qualitative dataset of information. The choice of the damage scale developed by Hu et al. [12] was motivated by their analysis of buildings damaged by debris flow occurred in Zhouqu (China) in 2010 and grounds on the China's Classification System of Earthquake Damage to Buildings [15].

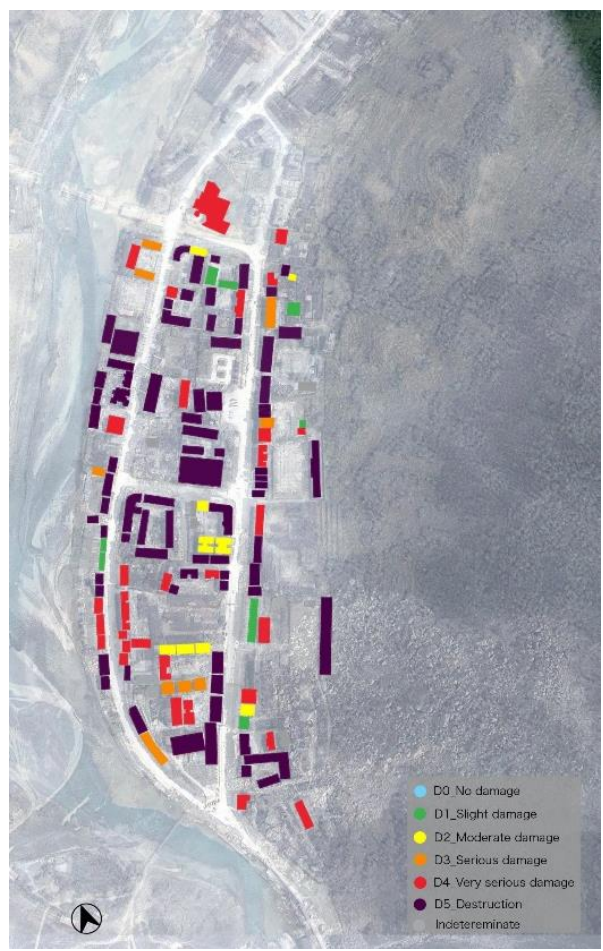

(a)

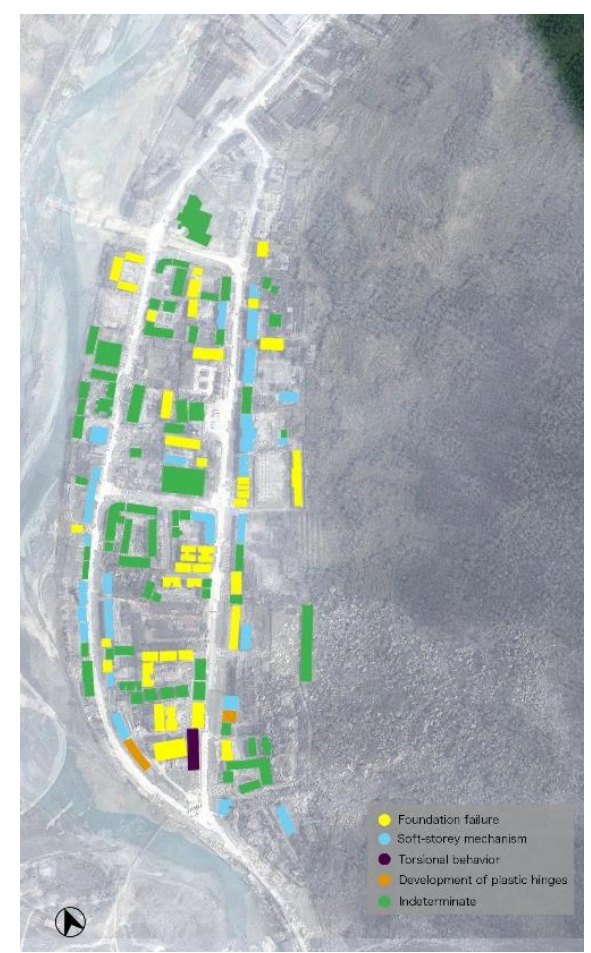

(b)

Fig. 5. Level (a) and typology (b) of damage to the building stock in Old Beichuan

The classification based on construction materials, as in Figure $6 b$, has been obtained based on the works devised by $[12-14,16]$, which involved mainly analysis conducted in the context of debris flows and seismic events. Lieping [16] and Hu [12] proposed overviews of the Chinese construction background in the aftermath of respectively a debris flow and the 2008 Wenchuan earthquake, allowing a deeper understanding of the most frequent structural typologies. The final classification is based on the field investigations carried out in December 2016 and July 2017, since they represent directly the materials effectively adopted in that area, mainly RC frames and masonry buildings. 


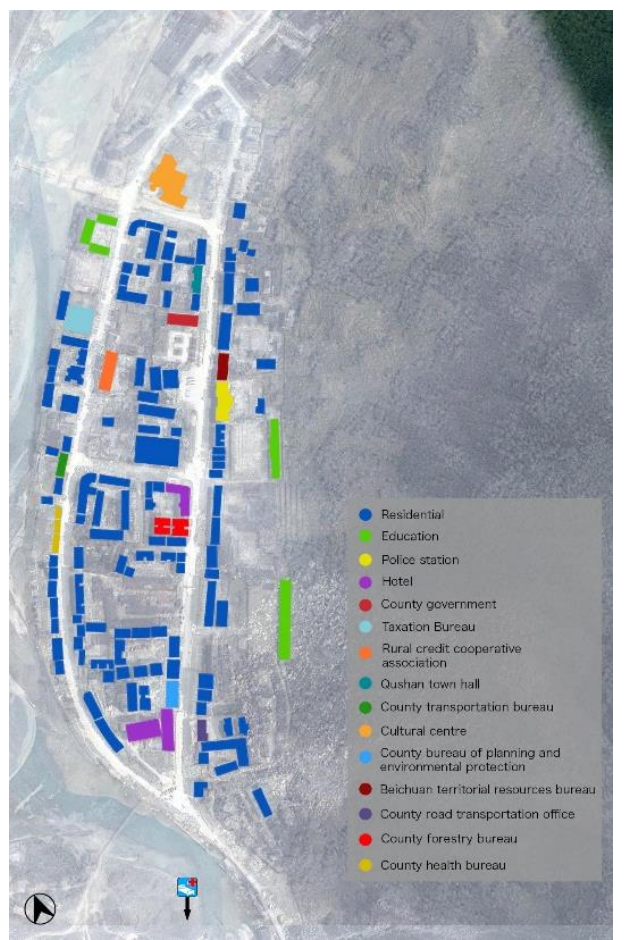

(a)

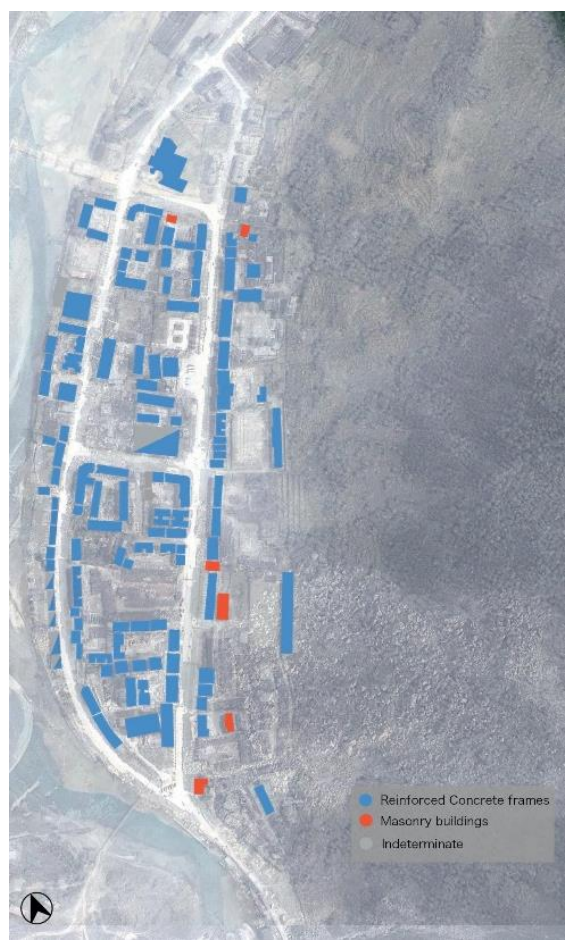

(b)

Fig. 6. Building functions (a) and construction materials (b) in Old Beichuan

The typology of damage summarized as in Figure $5 b$ has been assessed qualitatively combining the on-site investigations with the overview provided by Lieping et al. [16] regarding building disruptions detected in the aftermath of the Wenchuan Earthquake. Namely, the damage typologies are the following:

- Foundation system failure: consisting mainly in the incapability of the foundation of withstanding the soil deformation and hence leading to differential displacements in the superstructure;

- Soft-storey collapse-mechanism: primarily ascribed to a lack of stiffening elements at the ground level (e.g., infill walls). This collapse mechanism mainly affects RC frames;

- Overall torsional behavior: this is usually due to a wrong placement of stiffness and mass centers in the structure leading to the development of torsional actions given a torque generated between the two centers;

- Development of plastic hinges: this mechanism happens when in particular sections of the structure the solicitation forces the section to exploit its deformational plastic abilities. 


\section{Discussion}

The strong interconnection between the socio-organizational and physical networks constituting the overall urban $\mathrm{CN}$ and how this interlaces with resilience is showed in both Figures 3 and 4 . The devised multi-dimensional mapping shows how the gathered information are complimentary to the demand for a strong level of cooperation particularly needed prior to the hazard occurrence (i.e., disaster prevention) and in its aftermath (i.e., post-disaster response). These phases consists in fact in the ones that can influence the most the response of the physical system to the hazard and entail the highest level of planning and a horizontal collaboration across the different actors of the virtual system.

The mapping appears to be consistent with the conceptualization proposed in Figure 3 and also with the information gathered in site in relation to the post-disaster response. In fact, Figure 1 shows that the road network has not been designed to be redundant, implying both a poor level of strategic planning in the preliminary phase and a scarce site-analysis. This lack of foresight and interrelation between the CN components lead to the incapability of emergency rescue systems to access the area once the three main access points have been compromised, forcing civilians to compensate the absence of emergency plans. It has been in fact acknowledged from the site investigation that in the aftermath of the seismic event the Water and Agricultural Machinery Bureau of Old Beichuan provided numerous public water emergency points in order to supply water to the survivors also repairing damaged water points that prevented people from accessing potable water. On a different note, it is worth pointing that no fire brigade headquarter has been detected in the investigated area of Old Beichuan.

Figure 3 shows that construction materials and in general the structural nature and its design influence the whole resilience cycle, apart from the post-response phase. In particular, this dimension is the only one that can damp the disaster propagation because it is impossible to intervene on a structure during an ongoing hazard. Considering also the mapping provided in Figure $6 \mathrm{~b}$ and the overall level of disruption registered as in Figure 5a, it becomes clear that this dimension tightly interlace with the level and typology of the damage, which consequently have the function to inform designers, stakeholders and decision-makers nodes in general about new potential constructions and preventive strategies following to the recovery. Therefore, the information acquired from the multi-dimensional mapping have scope of transferring information from the physical to the socio-organizational network in order to prioritize post-response and recovery strategies but also nurturing the knowledge for future preventive strategies.

With particular regard to the context of Old Beichuan County, an overall fragmentation of the different $\mathrm{CN}$ entities has been registered, showing a lack of preventive strategies for post-response planning and a poor resilience achieved at the physical network level. This led to a negative chain of events in which the non-collaborative nature of this particular urban network resulted in a complete incapability of response and recovery from the event, despite the significant efforts of local emergency services. As pointed out in section 3 and shown in Figures $4 \mathrm{a}$ and $4 \mathrm{~b}$, a strong correlation between the seriousness of the damage and its geotechnical-based nature has been detected. In particular it has been observed a predominant soft-storey behavior failure mechanism induced by vertical differential settlements at the foundation level. This reveals an evident fragmentation between the nodes involved in the preliminary design phase of the 
different buildings. In particular, this applies to all the technical entities involved in site analysis and design (e.g., geologists, engineers, territorial planners, local authorities) and their interaction with budget-holder nodes, such as stakeholders and governmental nodes. As a matter of fact, in most cases stakeholders and clients are reluctant to invest significant amount of money to devise preventive measure in face of events with a probabilistic occurrence [7], such as seismic hazards.

On the other side and in light of the mapping, no particular correlation has been observed between the level of damage in public and private buildings. It is expected that public-owned buildings (e.g., schools) have undergone a lower level of damage, owing to more performing structural countermeasure thanks to the stronger financial support coming from the involvement of strong investors such as public authorities or governments. Despite that, a corresponding level of collaboration has not been achieved and this clearly reflected in an unsuitable planning with regards to both physical elements (e.g., structures and infrastructures) and strategies (e.g., post-disaster response), affective the overall performance of the network.

\section{Conclusions}

This paper presented an integration of the concepts of CNs and resilience in the specific seismic hazard scenario of Old Beichuan in the aftermath of the 2008 Wenchuan earthquake. To characterize the urban framework and highlight the underpinning connections, five dimensions have been highlighted and mapped (i.e., urban connectivity, building function, construction technology, damage typology and level). The conceptualization of the urban $\mathrm{CN}$ as the integration of socio-organizational and physical networks allowed to highlight its resiliency level in face of a seismic hazard. It is been outlined how the overall network resilience is highly influenced by the level of collaboration at the socio-organizational level, which particularly reflects in preventive strategies and post-disaster response.

The analysis allowed to reveal that a significant fragmentation of the nodes involved at the socio-organizational network level reflected in poor construction quality, inefficient rescuing services and preventive strategies. The building stock has been incapable of damping the disaster propagation due to unsuitable design choices, making impossible any type of recovery. Stakeholders and designers have to be sensitized about the long-term consequences of the decisions taken prior to any actions, considering that the high level of interdependency of urban network leads to proportionate likelihood for disaster chains. A consideration of the urban framework as a $\mathrm{CN}$ embedding resilience can provide a comprehensive overview of the different nodes composing the socioorganizational network. This aspect is crucial in order to achieve a targeted planning of how to address the urban CN's resilience in each of its phases and for each of the dimensions that have an effect on it.

\section{Acknowledgements}

This research is supported by the Building Research Establishment (BRE) and the National Environment Research Council (NERC) under grant NE/N012240/1. 


\section{References}

1. Camarinha-Matos, L.M., Afsarmanesh, H.: Collaborative Networks. In: Wang, K., Kovacs, G.L., Wozny, M., and Fang, M. (eds.) Knowledge Enterprise: INTELLIGENT STRATEGIES IN PRODUCT DESIGN, MANUFACTURING AND MANAGEMENT 2006, pp. 26-40. Springer US, Boston, MA (2006).

2. Jassbi, J., Camarinha-Matos, L.M., Barata, J.: A Framework for Evaluation of Resilience of Disaster Rescue Networks. In: Risks and Resilience of Collaborative Networks, IFIP AICT series 463/2015, Springer, pp.146-158. (2015).

3. Barthe-Delanoë, A.-M., Bénaben, F., Carbonnel, S., Pingaud, H.: Event-Driven Agility of Crisis Management Collaborative Processes. In: 9th INTERNATIONAL ISCRAM CONFERENCE 2012, pp. 1-5., Vancouver, Canada (2012).

4. Shim, J., Kim, C.-I.: Measuring Resilience to Natural Hazards: Towards Sustainable Hazard Mitigation. Sustainability (7), 14153-14185 (2015).

5. Comune di Bologna Iperbole, http://dru.iperbole.bologna.it/cartografia, last accessed 2018/04/13.

6. Uzielli, M., Catani, F., Tofani, V., Casagli, N.: Risk analysis for the Ancona landslide-II: estimation of risk to buildings. Landslides 12(1), 83-100 (2015).

7. Cerè, G., Rezgui, Y., Zhao, W.: Critical review of existing built environment resilience frameworks: Directions for future research. Interantional Journal of Disaster Risk Reduction 25, 173-189 (2017).

8. Jung, K., Song, M.: Linking emergency management networks to disaster resilience: bonding and bridging strategy in hierarchical or horizontal collaboration networks. Quality and Quantity 49(4), 1465-1483 (2015).

9. Andrew, S.A., Carr, J.B.: Mitigating Uncertainty and Risk in Planning for Regional Preparedness: The Role of Bonding and Bridging Relationships, Urban Studies 50(4), 709-724 (2013).

10. Mischen, P.A.: Collaborative Network Capacity. Public Management Review 173(3), 380-403 (2015).

11. Ouyang, M., Dueñas-Osorio, L.: Time-dependent resilience assessment and improvement of urban infrastructure systems. Chaos: An Interdisciplinary Journal of Nonlinear Science 22(3), 033122 (2012).

12. Hu, K.H., Cui, P., Zhang, J.Q.: Characteristics of damage to buildings by debris flows on 7 August 2010 in Zhouqu, Western China. Natural Hazards and Earth System Science 12(7), 2209-2217 (2012).

13. Okada, S., Takai, N.: Classifications of structural types and damage patterns of buildings for earthquake field investigation. In: 12th WORLD CONFERENCE ON EATHQUAKE ENGINEERING, Auckland,New Zealand (2000).

14. Mavrouli, O., Fotopoulou, S., Pitilakis, K., Zuccaro, G., Corominas, J., Santo, A., Cacace, F., De Gregorio, D., Di Crescenzo, G., Foerster, E., Ulrich, T.: Vulnerability assessment for reinforced concrete buildings exposed to landslides. Bulletin of Engineering Geology and the Environment 73(2), 265-289 (2014).

15. Classification of earthquake damage to buildings and special structures. National Standard of China, GB/T 24335-2009 (2009).

16. Lieping, Y., Xinzheng, L., Zhe, Q., Peng, F.: Analysis on Building Seismic Damage in the Wenchuan Earthquake. In: The 14th WORLD CONFERENCE ON EATHQUAKE ENGINEERING, Beijing, China (2008). 